\title{
Evaluation of potential drug-drug interactions among patients with chronic kidney disease in northeastern Nigeria
}

\author{
Roland N Okoro, Victor T Farate \\ Department of Clinical Pharmacy and Pharmacy Administration, Faculty of Pharmacy, University of Maiduguri, Maiduguri, Nigeria.
}

\section{ABSTRACT}

Background: Potential drug-drug interactions (pDDIs) may not manifest clinically in patients who are treated with multiple pharmaceutical agents, but when they do they can produce adverse outcomes. In patients with chronic kidney disease (CKD), the frequent use of multiple agents to manage this condition and its complications puts these patients at increased risk for DDIs. We determined the prevalence of pDDIs in CKD patients in two Nigerian hospitals and investigated possible predictors of pDDIs.

Methods: This cross-sectional study involved patients with CKD who attended the nephrology unit of the University of Maiduguri Teaching Hospital and the medical outpatients clinic of the State Specialist Hospital in Maiduguri, Nigeria. We collected prescriptions, clinical data and laboratory data from the medical files of patients seen between January 2013 and December 2017. Descriptive and inferential statistics were used to analyse the data.

Results: The study included 201 patients. A total of 273 pDDls were identified in 166 patients (83\%). These pDDIs included 30 unique drug interactions, the most common being between ferrous sulphate and calcium carbonate (seen in $46 \%$ of patients with pDDIs), followed by lisinopril and furosemide (8\%). The proportion of clinically significant interactions was only $2 \%$. There was a positive association between pDDIs and the total number of drugs prescribed $(P<0.001)$.

Conclusions: A high prevalence of pDDls was documented among Nigerian patients with CKD. The bulk of the interactions were related to the co-prescription of ferrous sulphate and calcium carbonate. The total number of drugs prescribed was a significant predictor of pDDls. We recommend routine screening of prescriptions of CKD patients for potential pDDIs.

Keywords: chronic kidney disease; potential drug-drug interactions; Nigeria.

\section{INTRODUCTION}

Chronic kidney disease (CKD) is one of the main global health problems, especially in developing nations. Its prevalence in Nigeria ranges from $6 \%$ to $12 \%$ [ I-4]. Patients with CKD are at increased risk for drug-drug interactions (DDIs) because of the use of multiple pharmaceutical agents and alterations in their pharmacodynamics and pharmacokinetics [5]. Not all potential DDls (pDDIs) may manifest clinically, but when they do they can produce adverse outcomes such as treatment failure or drug-induced toxicity with resultant increased costs, morbidity and even mortality [6-9]. The pDDI refers to the likelihood of a drug altering the effects of another when both are administered simultaneously [I0]. The reported prevalence of pDDls in CKD populations ranges from $76 \%$ to $89 \%[1 \mid-16]$. This underscores the need for clinicians to always screen for pDDls in this high-risk population.

As kidney function deteriorates in patients with CKD, more medications are needed to control the many complications of this disease, such as metabolic and bone disorders, anaemia, dyslipidaemia and cardiovascular disorders [6]. The main factor associated with pDDIs in CKD patients is, therefore, polypharmacy [17]. 
An earlier study on pDDls among CKD patients in the southwestern part of Nigeria reported a high prevalence of $96 \%$ [18], while another study from the southeastern part of the country reported a prevalence of 64.0\% [17]. We aimed to determine the prevalence and predictors of pDDIs among CKD patients in northeastern Nigeria.

\section{METHODS}

This study was a cross-sectional audit of the prescriptions of CKD patients who attended the nephrology unit of the University of Maiduguri Teaching Hospital and the medical outpatients unit of the State Specialist Hospital in Maiduguri, Nigeria, from January 2013 to December 2017. All patients diagnosed with CKD (stages $1-5$, including those on dialysis), who had at least two oral medications concurrently prescribed, comprised the study population.

Data extracted from the patients' medical files included their demographic information, concurrent medications, and clinical characteristics such as comorbidities (other chronic diseases) and last recorded serum creatinine. Estimated glomerular filtration rate (eGFR) was calculated from serum creatinine using the Modification of Diet in Renal Disease (MDRD) equation. The eGFR (in $\mathrm{mL}$ / $\mathrm{min} / 1.73 \mathrm{~m} 2$ ) was used to group patients into different CKD stages: stage I, eGFR $\geq 90$; stage 2, eGFR 60-89; stage 3a, eGFR 45-59; stage 3b, eGFR 30-44; stage 4, eGFR 15-29; stage 5, eGFR < 15 [19]. Each patient's list of medications was screened using the Omnio ${ }^{\circledR}$ drug interaction checker [20]. The identified pDDIs were graded according to their level of severity. Each pDDI was categorized as "moderate" (use only in special circumstances), "severe" (potential for serious interactions regular monitoring required or use of alternative medication) or "contraindication" (should be avoided; the risk outweighs the benefit).

Descriptive statistics (frequency, percentage, mean \pm standard deviation (SD), range) were used to summarize the data. Comparisons among patients with and without pDDI were performed using the chi-square test for categorical variables and Student's t-test for numerical variables. Multiple linear regression was used to investigate the predictors of pDDls. A $P$ value $<0.05$ was considered statistically significant. Statistical Package for Social Sciences (SPSS) for Windows ${ }^{\circledR}$ version 21.0 (SPSS Inc, Chicago, USA) was used for the analyses.

The Research and Ethics Committees of the study hospitals granted the ethical clearance with approval numbers UMTH/REC/I7/II8 and SSH/GEN/64I.

\section{RESULTS}

Table I presents the demographic data of the study population. There were 20I CKD patients included, with
66\% being female. Most were between 40-59 years old and the mean age was 49.5 years. Hypertension (35\%) was the most common comorbidity encountered and about $70 \%$ of the patients were at CKD stage 5. Four hundred and twenty-eight prescriptions containing at least two concurrent prescribed oral medications were examined. Most patients (85\%) used 5 or more drugs with a mean of $5.8 \pm 1.5$ and a range of $2-9$ drugs.

Two hundred and seventy-three pDDls were observed in 166 (83\%) patients. The mean number of pDDls per patient in this group was $1.4 \pm 1.0$, with a range of $1-5$. The majority (87\%) had one or two pDDls, and only 1.2\% had 5 pDDls (Figure I).

Of the 273 pDDls, 98\% were of moderate severity, $0.4 \%$ were severe interactions, and $1.8 \%$ were for contraindicated drug combinations. We identified 30 different drug interacting combinations, ferrous sulphate plus calcium carbonate (in 46\%) being the most frequent combination encountered. The prevalence of highly clinically significant interactions was only 1.8\%. The pDDls identified by this study and their potential adverse outcomes are listed in Table 2.

Multiple linear regression analysis (Table 3) revealed a positive relationship between the number of pDDIs and the total number of drugs prescribed $(P<0.00$ I).

\section{DISCUSSION}

This study found a high prevalence of pDDIs in our CKD population, with most being of moderate severity and few of high clinical importance. The number of medications prescribed for each patient was a major predictor of pDDls.

In our study, the prevalence and severity of pDDls in CKD patients was similar to that reported by an earlier study conducted in the southwestern part of the country [18]. That study also reported a low prevalence of contraindicated drug combinations (0.1\%) [18]. A similar prevalence has been reported in India, Palestine and Pakistan [12-14] whereas lower prevalence rates have been reported in Brazil and India (56.9\% and 66.8\%, respectively) $[11,21]$. Variations in the prescribing habits of physicians across countries and hospitals could be responsible for this observed difference. Regarding the severity of pDDls, studies from many countries have reported high rates of pDDls of moderate severity $[1|| 2,, \mid 4-16]$.

The mean number of pDDls per affected patient recorded by our study is similar to the 1.5 reported in an earlier investigation from the southwestern part of the country [18], 
Table I. Distribution of patients with CKD by occurrence of potential drug-drug interactions (pDDIs).

\begin{tabular}{|c|c|c|c|c|}
\hline Variable & $\begin{array}{l}\text { All patients } \\
\mathrm{n}=201(\%)\end{array}$ & $\begin{array}{l}\text { With pDDIs } \\
\mathrm{n}=166(\%)\end{array}$ & $\begin{array}{c}\text { Without pDDls } \\
\mathrm{n}=35(\%)\end{array}$ & $P$ value \\
\hline \multicolumn{5}{|l|}{ Hospital category } \\
\hline Secondary & $100(49.8)$ & $74(44.6)$ & $26(74.3)$ & 0.001 \\
\hline Tertiary & $|0|(50.2)$ & $92(55.4)$ & $9(25.7)$ & \\
\hline \multicolumn{5}{|l|}{ Sex } \\
\hline Female & $133(66.2)$ & $110(66.3)$ & $23(65.7)$ & 0.950 \\
\hline Male & $68(33.8)$ & $56(33.7)$ & $12(34.3)$ & \\
\hline Age in years & $49.5 \pm 14.5$ & $48.9 \pm 14.0$ & $52.1 \pm 16.8$ & 0.244 \\
\hline \multicolumn{5}{|l|}{ CKD stage } \\
\hline 3 & $19(9.5)$ & $17(10.2)$ & $2(5.7)$ & 0.309 \\
\hline 4 & $43(21.4)$ & $38(22.9)$ & $5(14.3)$ & \\
\hline 5 & $139(69.2)$ & II | (66.9) & $28(80.0)$ & \\
\hline \multicolumn{5}{|c|}{ Number of comorbidities } \\
\hline None & $95(47.3)$ & $9(5.4)$ & $2(5.7)$ & 0.016 \\
\hline । & $95(47.3)$ & 7I (42.8) & $24(68.6)$ & \\
\hline$\geq 2$ & II (5.5) & $86(51.8)$ & $9(25.7)$ & \\
\hline Number of drugs (SD) & $5.8(1.5)$ & $6.1(1.3)$ & $4.5(1.5)$ & $<0.001$ \\
\hline Range & $2-9$ & $3-9$ & $2-8$ & \\
\hline
\end{tabular}

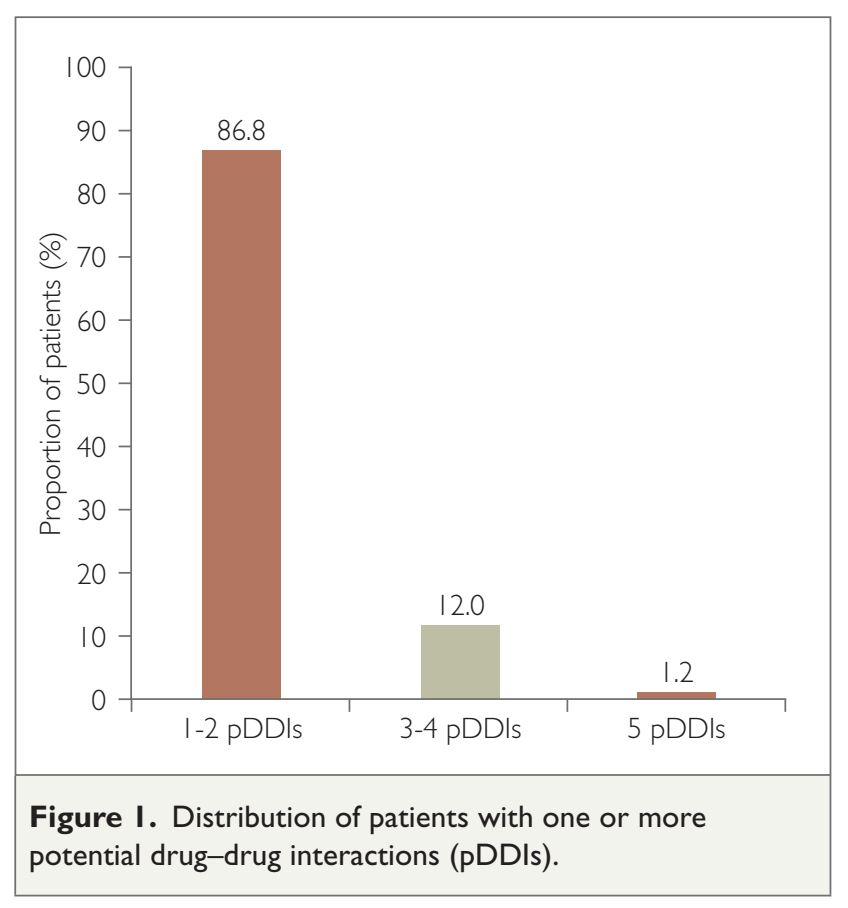

but lower than the range of 2.7-4.I reported in other studies [|2,|5,2|]. The differences from studies outside Nigeria may relate to variations in the prescribing habits of physicians of different nations.

The most frequent interacting drug combinations identified
Concomitant use of calcium may decrease the intestinal absorption of orally administered iron. Therefore, when these two drugs are co-prescribed for CKD patients, physicians and pharmacists should counsel these patients to take the ferrous sulphate at least two hours apart from the calcium carbonate, to prevent this unwanted interaction. This finding is in agreement with some studies $[|1| 6,, \mid 8]$, but differs from others, which reported ascorbic acid/cyanocobalamin, calcium carbonate/amlodipine, ferrous sulphate/omeprazole, lisinopril/furosemide, or aspirin/clopidogrel as the most frequent combinations for pDDIs [12-|4, 17,2|].

The number of prescribed medications was a significant predictor of pDDls in our study, consistent with the results of others $[14,17,22]$. Physicians prescribing medications for these patients should ensure rational prescribing and avoidance of unnecessary medications to reduce the pill burden and the risk of DDls in this patient population. The use of clinical decision support systems could assist in this regard. Clinical pharmacists should also screen prescriptions for pDDls before dispensing medications to CKD patients and, when minor or moderate interactions are detected, patients should be counselled on how to separate the administration of the drugs that are involved. 
Table 2. Potential drug-drug interactions among patients with chronic kidney disease.

\begin{tabular}{|c|c|c|c|}
\hline Severity level & Object drug_precipitant drug & n (\%) & Potential adverse outcomes \\
\hline $\begin{array}{l}\text { Contraindication" } \\
N=5(1.8 \%)\end{array}$ & coartem_ciprofloxacin & $5(1.8)$ & $\begin{array}{l}\text { Increased risk of QTc-interval prolongation and } \\
\text { life-threatening cardiac arrhythmias }\end{array}$ \\
\hline $\begin{array}{l}\text { Severe } \\
N=1(0.4 \%)\end{array}$ & erythromycin_amlodipine & I $(0.4)$ & $\begin{array}{l}\text { Increased risk of hypotension, shock, acute kidney } \\
\text { failure, and sudden death }\end{array}$ \\
\hline \multirow[t]{28}{*}{$\begin{array}{l}\text { Moderate } \\
N=267(97.8 \%)\end{array}$} & ferrous sulphate_calcium carbonate & $125(45.8)$ & Decreased absorption of iron \\
\hline & lisinopril_furosemide & $21(7.7)$ & Severe postural hypotension \\
\hline & captopril_furosemide & $18(6.6)$ & Severe postural hypotension \\
\hline & captopril_spirinolactone & $18(6.6)$ & Hyperkalaemia \\
\hline & ciprofloxacin_ferrous sulphate & $14(5.1)$ & Decreased effectiveness of ciprofloxacin \\
\hline & ferrous sulphate_antacid & $14(5.1)$ & Decreased absorption of iron \\
\hline & methyldopa_ferrous sulphate & $10(3.7)$ & Decreased efficacy of methyldopa \\
\hline & ciprofloxacin_calcium carbonate & $7(2.6)$ & Decreased effectiveness of ciprofloxacin \\
\hline & lisinopril_aspirin & $7(2.6)$ & Decreased antihypertensive effects of lisinopril \\
\hline & diclofenac_furosemide & $5(1.8)$ & $\begin{array}{l}\text { Decreased antihypertensive and diuretic } \\
\text { actions of furosemide }\end{array}$ \\
\hline & lisinopril_spirinolactone & $4(1.5)$ & Hyperkalaemia \\
\hline & ciprofloxacin_antacid & $3(1.1)$ & Decreased effectiveness of ciprofloxacin \\
\hline & captopril_aspirin & $2(0.7)$ & Decreased antihypertensive effects of captopril \\
\hline & captopril_diclofenac & $2(0.7)$ & $\begin{array}{l}\text { Decreased antihypertensive effects of captopril and } \\
\text { deterioration of renal clearance }\end{array}$ \\
\hline & levofloxacin_ferrous sulphate & $2(0.7)$ & Decreased effectiveness of levofloxacin \\
\hline & lisinopril_torsemide & $2(0.7)$ & Severe postural hypotension \\
\hline & losartan_furosemide & $2(0.7)$ & Severe postural hypotension \\
\hline & atenolol_nifedipine & । (0.4) & Increased toxic effects of both drugs \\
\hline & atenolol_prazocin & I (0.4) & Increased hypotensive action of prazocin \\
\hline & cefuroxime_calcium carbonate & । $(0.4)$ & Decreased efficacy of cefuroxime \\
\hline & ciprofloxacin_multivitamins & । (0.4) & Decreased effectiveness of ciprofloxacin \\
\hline & digoxin_furosemide & I (0.4) & Increased arrhythmias \\
\hline & levofloxacin_calcium carbonate & I (0.4) & Decreased effectiveness of levofloxacin \\
\hline & levofloxacin_multivitamins & । (0.4) & Decreased effectiveness of levofloxacin \\
\hline & lisinopril_diclofenac & I (0.4) & Decreased antihypertensive effects of lisinopril \\
\hline & lisinopril_naproxen & I (0.4) & Decreased antihypertensive effects of lisinopril \\
\hline & phenytoin_calcium carbonate & I (0.4) & Decreased levels and effectiveness of phenytoin \\
\hline & risperidone_levofloxacin & I (0.4) & $\begin{array}{l}\text { Increased risk of QTc-interval prolongation } \\
\text { and arrhythmias }\end{array}$ \\
\hline
\end{tabular}


Table 3. Multivariable analysis of factors associated with number of potential drug-drug interactions.

\begin{tabular}{|c|c|c|c|c|}
\hline Variable & Coefficient & $P$ value & \multicolumn{2}{|c|}{$95 \%$ confidence interval } \\
\hline Hospital category & 0.016 & 0.830 & -0.263 & 0.328 \\
\hline Number of drugs prescribed & 0.409 & $<0.00$ I & 0.184 & 0.394 \\
\hline Number of comorbidities & 0.134 & 0.051 & -0.001 & 0.313 \\
\hline
\end{tabular}

Among the limitations of our study is the fact that we detected only pDDls, which may not manifest clinically. Another is that the $O$ mnio ${ }^{\circledR}$ drug interaction checker used does not take into consideration the prescribed dose, frequency of administration, route of administration, and duration of medication use.

\section{CONCLUSIONS}

There is a relatively high prevalence of pDDls among patients with CKD in northeastern Nigeria. Most were of moderate severity, and the most common was between calcium carbonate and ferrous sulphate. The number of medications prescribed for each patient was a significant predictor of pDDIs and we therefore recommend that physicians and pharmacists attending to these patients should use clinical decision support systems or drug-drug interaction software to detect and prevent detrimental pDDIs.

\section{Acknowledgments}

Our profound gratitude goes to the staff of the medical record departments of the study hospitals.

\section{REFERENCES}

I. Kadiri S, Arije A. Temporal variations and meteorological factors in hospital admissions of chronic renal failure in South West Nigeria. West Afr J Med. 1999; 18:49-5।.

2. Akinsola W, Odesanmi WO, Ogunniyi JO, Ladipo GO. Diseases causing chronic renal failure in Nigerians - A prospective study of 100 cases. Afr J Med Med Sci. 1989; 18:131-137.

3. Ulasi II, ljoma CK, Onodugo OD, Arodiwe EB, Ifebunandu NA, Okoye JU. Towards prevention of chronic kidney disease in Nigeria: A community-based study in Southeast Nigeria. Kidney Int Suppl. 2013; 3:195-201.

4. Oluyombo R, Ayodele OE, Akinwusi PO, Okunola OO, Akinsola A, Arogundade FA, et al. A community study of the prevalence, risk factors and pattern of chronic kidney disease in Osun State, South West Nigeria. West Afr J Med. 2013; 32:85-92.

5. Madero M, Gul A and Sarnak M. Cognitive function in chronic kidney disease. Semin Dial. 2008; 21:29-37.

6. Mason N. Polypharmacy and medication related complications in the chronic kidney disease patient. Curr Opin Nephrol Hypertens. 20I I; 20:492-497.

7. Cardone KE, Bacchus S, Assimon MM, Pai AB, Manley HJ. Medication-related problems in CKD. Adv Chronic Kidney Dis.
8. Baxter K. Stockley's Drug Interactions: a source book of interactions, their mechanisms, clinical importance and management. 10th edition. London: Pharmaceutical Press; 2014.

9. Edwards IR, Aronson JK. Adverse drug reactions: definitions, diagnosis, and management. Lancet. 2000; 356(9237): I255- 1259.

10. Alim MM, Silva LA, Leite IC, Silverio MS. Adverse events caused by potential drug-drug interactions in an intensive care unit of a teaching hospital. Rev Bras Ter Intensiva. 2015; 27:353-359.

I I. Sgnaolin V, Sgnaolin V, Engroff P, De Carli A, Figueiredo AE. Assessment of used medications and drug-drug interactions among chronic renal failure patients. Sci Med. 2014; 24(4):329-335.

12. Rama M, Viswanathan G, Acharya LD, Attur RP, Reddy PN, Raghavan SV. Assessment of drug-drug interactions among renal failure patients of nephrology ward in a South Indian tertiary care hospital. Indian J Pharm Sci. 2012; 74( I):63-68.

13. Al-Ramahi R, Afnan R, Raddad AR, Rashed AO, Bsharat A, Abu-Ghazaleh D, et al. Evaluation of potential drug-drug interactions among Palestinian hemodialysis patients. BMC Nephrol. 20 I6; 17:96.

14. Saleem A, Mashood I, Khan TM. Clinical relevancy and determinants of potential drug-drug interactions in chronic kidney disease patients: result from a retrospective analysis. Integr Pharm Res Pract. 2017; 6:7I-77.

15. Marquito AB, Fernandes NM, Colugnati FAB, de Paula RB. Identifying potential drug interactions in chronic kidney disease patients. J Bras Nefrol. 2014; 36(I):26-34.

16. Hedge S, Udaykumar P, Manjuprasad MS. Potential drug interactions in chronic kidney disease patients. A cross-sectional study. Int J Recent Trends Sci Technol. 20 I5; 16:56-60.

17. Chinwendu AK, Joda AE, Oyetunde OO, Udezi WA. Evaluation of drug-drug interactions among chronic kidney disease patients of nephrology unit in the University of Nigeria Teaching Hospital, Ituku-Ozalla, Enugu State. J Basic Clin Pharma. 2017; 8:S049-S053.

18. Fasipe OJ, Akhideno PE, Nwaiwu O, Adelosoye AA. Assessment of prescribed medications and pattern of distribution for potential drug-drug interactions among chronic kidney disease patients attending the Nephrology Clinic of Lagos University Teaching Hospital in Sub-Saharan West Africa. Clin Pharmacol. 2017; 9:125-132.

19. Levey AS, De Jong PE, Coresh J, El Nahas M, Astor B, Matsushita K, et al. The definition, classification, and prognosis of chronic kidney disease: a KDIGO Controversies Conference report. Kidney Int. 201।; 80:17-28.

20. Omnio drug interaction checker version 3.24.6 Aptus Health. Available at: http://www.omnio.en.aptoide.com.

21. Chacko SC, Shareef J, Kamath J. Assessment of drug-drug interactions in chronic kidney disease patients in nephrology unit of a tertiary care teaching hospital. Indo Am J Pharm Res. 2016; 6(03).

22. Chaliks R. Factors influence the potential drug interaction occurrence among hospitalized patients with chronic kidney disease at Labuang Baji Hospital Makassar. Int J Sci Basic Appl Res. 20 I5; 24(3):376-383. 